\title{
the fundamentals of restorative justice
}

\author{
John Braithwaite \\ School of Humanities \\ Law Program, RSSS, Australian National University
}

RESTORATIVE JUSTICE is conceived of in this essay as a process in which all the stakeholders affected by an injustice have the opportunity to discuss the consequences of the injustice and what might be done to put them right. This is a process conception of restorative justice by which what is to be restored is left open. Rather, the form of restoration of victims, of offenders and of communities that count are those found to be important in such a restorative justice process. Beyond the process conception, there is also a values conception of restorative justice. The key value is that because injustice hurts, justice should heal. Responding to pain with 'another spoonful of pain' ${ }^{1}$ is seen as a less satisfactory response than responding with healing or repair. A reason is that hurt tends to beget hurt, creating a vicious spiral of retribution and feuding. Alternatively, it is possible to flip this dynamic into one of healing begetting healing - a virtuous circle.

I have argued that the key value of restorative justice is non-domination. ${ }^{2}$ The active part of this value is empowerment. Empowerment means preventing the state from 'stealing conflicts' ${ }^{3}$ from people who want to hang on to those conflicts and learn from working them through in their own way. Empowerment should trump other restorative justice values like forgiveness, healing and apology, important as they are. This means that if stakeholders in 
an injustice wish to respond in a retributive way, taking empowerment seriously requires that they be allowed to opt for a retributive resolution to the injustice rather than a restorative outcome. But because non-domination is the fundamental value that motivates the operational value of empowerment, people are not empowered to breach fundamental human rights in their pursuit of revenge. So if a woman has shamed her partner by say sexual infidelity, rape is an unacceptable punitive response, indeed is an injustice that itself must be confronted by a non-dominating process. The fundamental human rights that almost all states enshrine in their law, if not in their political practice, must set limits on the domination community justice can impose. These laws include upper limits on the punishments that can be imposed for defined types of wrongdoing.

Participants are not empowered to shout and intimidate in restorative justice processes because the empowerment of the one is then purchased at the price of the domination of the many. Respectful listening is thus also a fundamental restorative justice value. Respectful listening is indeed integral to empowerment for reasons that have been eloquently articulated by Kay Pranis. ${ }^{4}$ Human beings are storytelling animals. You can tell how much power a person has by observing how many people listen attentively to his or her stories. It follows from this that we can empower the powerless by institutionalising more effective listening to their stories of injustice. This is what restorative justice is about: the deadly simple empowerment that comes from creating pacified spaces where we listen to those we feel have wronged us and those we think we may have wronged.

Vital, yet subsidiary, restorative justice values like forgiveness and apology are not values we actively seek to persuade people to manifest, in the way we do seek to actively persuade respectful listening. Forgiveness and apology are gifts; they only have meaning and power if they are freely chosen by those who give them in response to an injustice. Yet the theory of restorative justice is that by creating safe spaces where people listen respectfully to the stories of the other about the injustices they believe they have suffered, forgiveness and apology are 
more likely to issue. There is now quite a bit of empirical evidence that this empirical claim of the theory of restorative justice is broadly correct. ${ }^{5}$

The prescriptive normative content of restorative justice is therefore rather minimalist - non-domination, empowerment, respectful listening and a process where all stakeholders have an opportunity to tell their stories about the effects of the injustice and what should be done to make them right. There is a lot of other normative content to restorative justice. For example, most restorative justice advocates would see forgiveness, apology, remorse for the perpetration of injustice, healing damaged relationships, building community, recompense to those who have suffered, as important restorative justice values. But there is no prescription that these things must happen for the process to be restorative justice. The explanatory theory of restorative justice is that these things are more likely to happen under a restorative than under a retributive process. And indeed part of the normative theory of restorative justice is that because these things are more likely to happen under restorative than retributive justice, the latter is generally preferable, at least until it has proved incapable of dealing with the injustice.

The minimalism of the prescriptive content of restorative justice means there is no right or best model. This means we should have limited interest in whether a particular model of conferencing is superior to another circle process, whether the South African Truth and Reconciliation Commission process is superior to the processes of reconciliation being worked through in Bougainville (as discussed in a number of the chapters in this volume). Restorative justice is culturally plural, historically pragmatic and contextual about what might prove to be the best process to deal with an injustice that arises at any specific point in space and time. While there are many reasons why a more complex circle where all stakeholders sit together might make for more effective restoration with less troubling imbalances of power than a series of one on one mediations, there are contexts where the dyad heals better than the circle. So we cannot say that dyadic forms of mediation that individualise disputes in an all too Western a way do not qualify as restorative justice. 
Where there is a distinction to be made here, however, is that restorative justice is about dealing with injustice and it is not morally neutral about injustice. Again, injustice is defined in terms of domination and it is therefore seen as a bad thing. So restorative justice is a philosophy that rejects the moral neutrality of a mediation that defines everything in the morally neutral language of conflict. Alan Rumsey makes some interesting observations about how in the Western Highlands of Papua New Guinea community and conflict are not antithetical; conflict is one of the forms exchange may take through relationships that build the restorative justice virtue of communities. I am not suggesting here that Rumsey or the people he studied are morally neutral about conflict; but nor is it time that restorative justice theorists necessarily see conflict as bad. It is injustice they see as bad. The restorative justice concern with repairing injustice instead of conflict goes deeper than the empirical observation that sometimes conflict is integral to building a just community. For the normative theorist of restorative justice, a rape is not a conflict. Rather it is an injustice by virtue of the domination involved. Rape is the denial of a human right that is fundamental to citizens living without fear of being overwhelmed. Of course there are conflicts that are best dealt with in the morally neutral language of conflict and we are best to deal with them restoratively too. But whenever domination produces injustice, the moral obligation of the restorative justice advocate is to argue respectfully, but passionately if need be, for confronting the particular injustice.

The evaluation research literature on restorative justice is becoming increasingly encouraging that restorative justice can work well in many contexts to prevent injustice. ${ }^{6}$ But it is also clear that restorative justice often fails. Just as appeasement was not very effective in responding to Hitler, one would have to be a considerable optimist to believe that restorative justice would have worked better. That particular injustice unfortunately required a violent response to deter and incapacitate aggression and tyranny. Equally, the more local injustice of the rapist will often require the punitive response of locking him up. Yet the restorative justice advocate is reluctant to assume even that the 
tyranny of genocidal warfare or rape is always or generally best responded to punitively. For this restorative justice theorist at least, however grave the injustice, it is best first to explore the possibilities for a restorative resolution. On this view, we are best to be presumptively restorative and punitive only as a last resort.

The world has changed a lot, even since Hitler's time, in a way that means our restorative traditions are more valuable to us than our retributive traditions. Very little of the warfare since the collapse of the Soviet Union has been within the framework of the Westphalian system of states. Warlords who control fractions of states are more important players than the states' commanders-in-chief are. This means that the realist deterrence that worked to a degree within the diplomatic norms of the state system has less power. The more predictable framework for warfare, in which pragmatic statist power plays were once characteristic, is becoming increasingly replaced by the more cynical prisings open of cultural, racial and religious divides. In this new world, vicious circles are activated by which, for example, humiliation of the Muslim world fuels yet another cycle of violence. An old dynamic is regenerated with even more force in contemporary conditions. At the micro level of dealing with a simple injustice like theft, we live in a world where stakeholders in the crime are less and less likely to be contained within a single culture. The thief might be an Aboriginal Australian to whom the European prison is a punitive institution that prevents healing because he is removed from his country in which the healing engagement usually takes place. The victim may be Malaitan and the offender from Guadalcanal. We live in a world where intracultural justice traditions that were and are granted considerable legitimacy when deployed intraculturally often backfire badly inter-culturally. Therefore the stocks are rising in later modern conditions for a more culturally minimalist approach in which respectful listening provides the contextual empowerment of all participants, thereby enabling them to work together towards creative settlements, deemed just by all sides.

All societies have restorative traditions that have worked well for them intraculturally for a long time. Equally, all societies 
that I know have retributive traditions. These also often worked well in the past, in that societies that lacked them were often wiped out by more retributive societies: e.g. Carthage wiped out by Rome. My argument here is that while all societies have both restorative and retributive traditions on which they have drawn productively in the past, today their restorative traditions are likely to have comparatively more value than their retributive traditions. We can therefore conceive of a global social movement for restorative justice as one that encourages people to retrieve within their cultures those restorative traditions which have so often become overly suppressed by traditions of retribution whose negative force engendered ever more pernicious cycles of hurt begetting hurt.

Again, this requires us to be normatively minimalist about how a restorative justice process should work. If the family of a victim asks at the beginning of a restorative justice conference that they be allowed to utter a Christian or Buddhist prayer for healing, then we should not jump to the assumption that this is a morally inappropriate breakdown of the separation of church and the justice of the state. So long as the other stakeholders indicate that they are happy for the culture of the other to be manifested in this way, then there is no problem.

The normative minimalism I am advocating is also why I have a preference for the term restorative justice over the appealing claims for transformative justice as an alternative that have been raised in the essays by Margaret Jolly and Alan Rumsey in this volume. When Desmond Tutu describes the South African Truth and Reconciliation Commission as a restorative justice process, he obviously does not mean any determinate reading of restoration as restoration of the Apartheid that existed before armed struggle was launched. He does not mean restoration of an unjust political status quo. He means healing of injustice, restoration of a justice that is and always was our human right. Restorative injustice has no appeal. Again the distinction from morally neutral mediation is important here. Tutu also believes, as I do, that processes that heal injustice are also likely to promote reconciliation between people - 
forgiveness, apology and the restoration of trust in relationships that have been sundered by conflict. Further he believes that while restorative justice institutions are not the most fundamental institutions for confronting social injustice - not as fundamental as welfare and tax systems for example restorative justice increases the prospects for social justice reforms. While the South African state did not take up his Commission's recommendation of a special wealth tax to compensate victims of Apartheid, many South African corporations that benefited from Apartheid have in fact voluntarily contributed to this cause. While the restorative justice process is hardly a perfect vehicle for social justice and not the most central or strategic one, because it is built on a philosophy that views justice holistically (as implying nondomination) the prospects are that restorative justice will advance social justice rather than retard it. ${ }^{7}$

That said, it seems potentially destabilising of restorative justice to move from the minimalist prescriptive framework I have articulated and require it to pursue a particular vision of transformation. Cross-culturally that will be particularly difficult to accomplish. This is not to say that transforming communities into more mutually supportive, hospitable $\mathrm{e}^{8}$ societies is not a desirable second-level value of restorative justice. Indeed it is good to evaluate restorative justice programs according to the degree that they transform communities to mutually supportive practices, to forgive, to treat one another with greater dignity and so on. For example, Ruby Zarriga's (this volume) community development approach to restorative justice can be read as transformative in that limited sense of transformation by community development. Even this rather uncontroversial vision of transformation is not one I would want to make definitional of restorative justice in the sense that you could not call something restorative justice unless some significant community development was accomplished. Equally I would not want to make the healing of relationships or forgiveness, or crime prevention or any other feature of that whole host of other important second-order values, requirements for calling a 
program restorative. Non-dominated participation and dialogue about an injustice by stakeholders who listen respectfully are what might be the minimum requirements for a process to be restorative.

Under the umbrella of these minimum requirements can flourish a rich diversity of restorative practices. Each society must adapt restorative practices in ways that fit the custom of its cultures. Every society can learn from understanding the complex ways this adaptation plays out in cultures other than their own, especially in a world where other cultures are so often represented within their own borders. This volume demonstrates that the Pacific is a particularly rich field of restorative justice cultural diversity. Indeed it is hard to think of cultures that recently have had more influence on Western restorative practices than the Polynesians, particularly of New Zealand and Hawaii. Lesser known Melanesian diversity in restorative justice practice is documented in the essays of Alan Rumsey, John Tombot, Joemela Simeon, John Ivoro, Patrick Howley, Michael Goddard and Ruth Saovana-Spriggs, among others. There are cautionary as well as celebratory tales of peacemaking among these accounts.

Rita Naviti and Margaret Jolly both point out in their essays in this volume that power imbalances can mean that both formal justice and restorative or other customary forms of justice can equally be dangerous because they are equally grounded in power imbalances between men and women. It may be that there are contexts where formal justice will actually be more empowering for women than restorative justice is. There are certainly other contexts where the reverse is true. For example, Ruth Saovana-Spriggs shows how customary justice in Bougainville can empower women in particular ways if it is grounded in the culturally determined special power of women as inheritors and custodians of the land. She shows how the Bougainville Women for Peace and Freedom harnessed this gendered power to its peacemaking effectiveness. If there are contexts where both formal and informal justice might be configured to get around the power imbalances that normally 
favour men, then it may be that non-domination more than anything else requires the empowerment to choose restorative justice or the justice of courts. At the moment, especially with domestic violence, women in all cultures I know have unsatisfactory access to both restorative justice and the justice of the courts. Expanding access to both kinds of justice for women can expand the realm of undominated choice.

Inspiring as some of the stories of restorative peacemaking are in this volume, well typified by Alan Rumsey's account of the peacemaking prowess of the Kulka Women's Club and the Faipela Kansil in Papua New Guinea, it should be equally clear that there are circumstances where formal courtroom adjudication can be a check and balance on the informality that follows the furrows of domination.

\section{Endnotes}

1 Christie, Nils 1981. Limits to Pain.

2 Braithwaite, John and Philip Pettit 1990. Not Just Deserts: A Republican Theory of Criminal Justice; Braithwaite 2002. Restorative Justice and Responsive Regulation

3 Christie 1977. 'Conflicts as property'

4 Pranis, Kay 2001. 'Democratizing social control: restorative justice, social justice and the empowerment of marginalized populations'

5 Braithwaite 2002, Chapter 3

6 Ibid

7 Ibid and Chapter 5

8 Pavlich, George 2001. 'The force of community' 